\title{
Analysis on User Demand Behavior of University Library under the Network Environment
}

\author{
Yanhui Zhang
}

Jilin University, Changchun, Jilin, 130021

\author{
Keywords: User Demand, University Library, Network Environment
}

\begin{abstract}
In the network environment, the user demand behavior of university libraries has changed. This paper takes the Hebei University Library as an example to discuss the information demand behavior of university library users. The questionnaire survey method is used to collect user data, and the data processing is used to analyze the needs of library users in the network environment. The current state of behavior, user preferences, behavioral tendencies, and factors affecting demand behavior. Finally, the promotion strategy for existing users and potential users was proposed for the Hebei University Library.
\end{abstract}

\section{Introduction}

The focus of library services is not whether there is a larger building, whether there is more comprehensive database resources, but the simplicity, convenience and comprehensiveness of the reader service. The research on library users' demand behavior in the network environment is to investigate the user demand behavior information of Hebei University Library from different angles, to understand the user needs, and to improve the user service of the university library is the significance of the research. The user can choose the library service in a short period of time. On the one hand, the user will be more willing to choose such a convenient and quick service method. On the other hand, the user's selection time is shortened, which means that the frequency of enjoying the service is increased. In the same period of time, the library provides users with a richer service.

\section{The subject of user demand behavior in university libraries}

The subject of the act is the issuer and implementer of the activity. In this paper, the authorized student users of the university library are divided into the teacher user group and the student user group according to the responsibilities of the user in the school. The research object of this paper is the university book. Library student users. The student user groups of university libraries can be subdivided into college students and graduate groups according to their academic qualifications. According to the degree of use of the library, it can be divided into existing users and potential users.

Psychologist Maslow believes that human needs are hierarchical and that the level of demand is low to high. The information needs of student users in university libraries provide motivation for their information behavior. After a user's level of information needs are met, a new high-level information demand will be generated, and the user's demand level will continue to improve and the information demand will be continuous. In this paper, the needs of college library users are divided into low-level to high-level by Maslow's hierarchy of needs, and the growth time of university library users is limited to a learning cycle, which takes a student from the beginning of school to the time of graduation. Defined as a learning cycle.

The learning needs are the most basic needs of university library users to maintain their own academic work, including the needs of professional and public-related books and magazines and the relevant digital resources needed to complete the final exam and graduation design. If these needs are not met, it will affect the student's academics, and library users will choose other channels and methods to meet their needs. In this sense, academic needs are the most powerful driving force for users to use library behavior. In the hierarchy of needs theory, the demand on the basis of survival is 
the demand for security. For the library users at this stage, the demand for college students to complete the academic needs is the demand for finding a job. As we all know, a major problem faced by college students when they graduate is employment. In employment, not only must they meet the academic requirements, but also the professional skills and part of management knowledge related to the work. This requires university library users to acquire relevant skills and obtain professional qualifications during college study, which has created a demand for libraries.

University life is different from the test-oriented education in middle and high schools. Students have more time and space to tap their potential, develop their own character and develop their own fun. The hobbies of college students are not only extensive, but also multifaceted. In a new field or in areas that require deep development, libraries are required to provide relevant borrowing materials and literature resources to provide a strong guarantee for the overall development of students. At the same time, the library can launch theme activities to cultivate a wide range of interests of college students.

Self-fulfilling needs are people who need to work hard to realize their potential and call themselves what they expect. The university stage is the pedal for students to go out of the exam-oriented education and go to the society. After the students' needs for learning work and entertainment are met, they need to realize personal values, fulfill their personal wishes or dreams. Maximize your personal abilities, enhance your ability to solve problems, be independent and be good at doing things independently, strive to realize your potential, and fulfill the needs of everything that matches your abilities.

\section{Characteristics of user demand behavior in university libraries}

User needs are informative. The college entrance examination is equivalent to artificial screening of university library users, which provides a guarantee for the library users' knowledge level. Compared with other online users, university library users have academic and professional backgrounds, and the academic level will gradually improve, and the demand for information is more biased towards their knowledge. Therefore, university library users may not satisfy the library to provide purely external documents with external features, and more need to go deep into the internal characteristics of the literature to provide relevant knowledge unit content related to the needs. Specifically, users will process, absorb, and utilize the retrieved documents, and this series of processes will require deeper information needs.

User needs are continuous. The identity of the user in a learning cycle is constantly changing, and the user's demand for the library is constantly changing and continuous. User research and learning itself are continuous and cyclical. It is difficult for users to complete a large research project in a short period of time, and users need different information resources in different research and learning stages. Library user needs are a continuous, cumulative, and recurring process. Therefore, the information demand behavior of university library users is a continuous and gradual behavior.

\section{University library service improvement strategy based on user behavior analysis}

According to the impact of user demand behavior on library service content, this paper integrates library services into library products. The library products combine traditional library services, including information retrieval information query, and propose new service products based on the characteristics of user demand behavior in the network environment. Introduce fun equipment and theme display products in the library. According to the data analysis, the evaluation of the library environment by library users affects the use of the library by the users. The environment of the university library is mostly rigid and uninteresting, and the service origin is mostly scattered. It is difficult to have the same needs and the same hobbies. The users are grouped together, which is inconvenient for the communication between the readers and makes the user feel boring. In order to increase the user's interest in the use of the process and the closeness of the connection, the library can introduce fun seat products and theme display products. For example, according to the 
teacher-student relationship, student relationship, the seat can also be customized. For example, "couples", "roommates", "brothers", "sweet seats", "joining together for a good youth" or other topics, and slogans are posted on them, check-in. The library launches the theme display products to change the original classification according to the Chinese map method. The content required by the users with common needs can be collectively displayed according to the purpose of the user's use of the library. For example, "Special Subjects for the Fourth and Sixth Exams", "Public Examination Subjects", "Working Topics". Fun devices and theme displays can increase the interest of reading, create a new gimmick to attract users to the use of the library, and reduce the drawbacks of traditional book arrangement, enhance the pertinence and professionalism of library services, reduce users Search for blind spots and retrieval time.

Multimedia service. In the network environment, the information of the library is more diversified and personalized. From tape CDs to multimedia screenings and endless APPs, the requirements for the type of information required are more comprehensive. In addition to textual information, multimedia information such as sound, images and graphics is also desired. Therefore, under the new information type requirements, university libraries can add new forms of information service models. The library can include sound, video and other content in the form of providing services. For example, increase the library's "viewing and listening" room and play multimedia information such as sounds, pictures, and movies. Conduct a film screening theme based on current hot topics.

Information service based on social network platform. The rapid development of social networking sites, the spread of information based on social networking platforms has been widely developed, and these are called websites, and most of the college students use them. The university library establishes Weibo WeChat account, and the library sets up special jobs for daily operation management, including hot topic discussion, WeChat soft text, and various voting information. At the same time, the book promotion and Weibo WeChat will be combined to publish the latest information, search knowledge, book recommendation, campus life, wonderful book review and other related information on the Weibo WeChat platform. At the same time, the social network platform is a very good information collection platform. Library users can interact with the library directly through comments, comments, likes, and forwarding. According to the interaction of these platforms, university libraries can understand user needs and get feedback on service results. Professional data analysis can also be performed by crawling relevant data such as user search paths.

The construction of APP in university libraries. In today's era, people's dependence on mobile devices has increased, and search activities on mobile phones or tablets have surpassed searches on desktop computers. In order to adapt to the changes in the industry, libraries also need to establish more convenient service methods, and the construction of APP in college libraries has become the first choice. The APP design is based on simplicity and convenience. For example, design a rolling broadcast section to play related topic book information, and follow up on current events to make regular updates.

Establish a student association for university libraries. The student associations of university libraries are organized by university libraries and are directly managed by the library. It can be initiated by library teachers to organize students, organize relevant departments, set up activity organization units, select community members, formulate activity charters, and initiate library-related activities.

\section{Conclusion}

In the current network environment, mobile networks are faster and electronic devices are becoming more advanced. The user's demand for service content in the process of using the library is increased, not only limited to the library's ability to provide rich reading materials and a spacious reading environment, but also the need for multimedia materials, printing and copying, and other related equipment. WIFI hotspots, the provision of network equipment. In the service channel, the number of users and network users in the library is not much different, and the users in the library 
have higher requirements for the library environment. In terms of service methods, users are more inclined to take the initiative of the library.

\section{References}

[1] Zeng Xuelian. Research on Library User Information Behavior in Big Data Environment [J]. Journal of the Party Committee of Fujian Provincial Committee of the Communist Party of China, 2015,(1):99-102

[2] Yuan Jing, Wang Chunying, Jia Congcong. Empirical Investigation and Analysis of User Information Behavior in Colleges and Universities under Mobile Network [J]. Information Theory \& Practice, 2015, (6): 93-97

[3] Gu Liping. Academic Information Retrieval Behavior in Web.2.0 Environment [J]. Library and Information Science, 2008(6:69-74)

[4] Ye Xiaohui. User Relationship Management Strategy of University Library Based on Reader Information Behavior Analysis [J]. Information, 2010.

[5] Li Guicheng. On the Countermeasures to Regulate the User Information Behavior of University Libraries, Library Journal [J]. Library Journal, 2010. 